\title{
A study of the prevalence of potentially inappropriate medication in elderly in a tertiary care teaching hospital in the state of Odisha
}

Supriya Pradhan, Abinash Panda, Meerabai Mohanty ${ }^{1}$, J. P. Behera, Y. R. Ramani, P. K. Pradhan

Departments of Pharmacology and ${ }^{1}$ House Staff, MKCG Medical College, Berhampur, Odisha, India

Address for the Correspondence: Dr. Supriya Pradhan, Department of Pharmacology, MKCG Medical College, Berhampur, Odisha, India. E-mail: drsupriyapradhan.sp3@ gmail.com

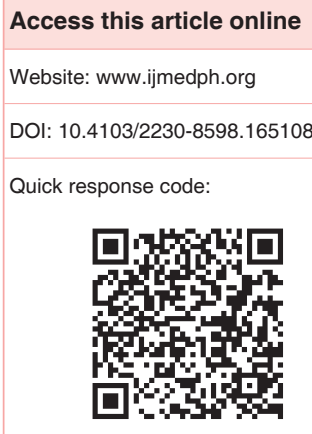

Introduction: Quality and safety of prescribing in older people remains a global healthcare concern. Inappropriate prescribing in the elderly population is now considered a major public health issue because of its direct association to morbidity, mortality and wastage of health resources. The study was initiated to study the prevalence of potentially inappropriate medications (PIMs) in elderly patients coming to seek health care in a tertiary care teaching hospital in Odisha. Materials and Methods: 2012 AGS Beers Criteria was used to analyse the inappropriateness of the prescriptions in 700 new as well as old patients of either sex who had completed 65 years of age as on 30th September 2013. Data obtained was analyzed with the help of SPSS version 20.0. Multivariate logistic regression was applied to find out the predictors of PIM. Results: $21.86 \%$ patients were prescribed at least one potentially inappropriate medication. Most of the drug use was seen in the age group of 65-74 years. Multivariate logistic regression analysis showed that increased number of concurrent medications use (OR: $1.95, \mathrm{Cl}: 1.19-3.01, \mathrm{P}=<0.01)$ was the predictor of inappropriate medication use as per 2012 AGS Beers Criteria. Age, gender and co-morbidity did not influence the use of inappropriate drugs. Conclusion: Inappropriate prescribing to elderly patients is influenced by the total number of drugs prescribed to an elderly patient. There is a need to improve the prescribing pattern in elderly. This will reduce the occurrence of adverse drug reactions, cost of treatment, and increase compliance in elderly patients.

Key words: Beers criteria (2012), elderly, potentially inappropriate medication

\section{INTRODUCTION}

Over the past century, life expectancy has increased dramatically. Between 2000 and 2050, the number of older adults worldwide is expected to increase from 420 to 974 million. ${ }^{[1]}$ India had an estimated elderly population of about 96 million, and this is expected to reach over 316 million by $2050 .{ }^{[2]}$ In the U.S., elderly age group comprise $12 \%$ of the population but receive $30 \%$ of all prescriptions. ${ }^{[3]}$ This social transformation represents a challenge to provide appropriate, affordable and accessible health service to this vulnerable age group.

Inappropriate prescribing in the elderly population is now considered a major public health issue because of its direct association to morbidity, mortality and wastage of health resources. Up to $30 \%$ of hospital admissions in older people are related to adverse drug events. ${ }^{[4]}$ Older people often experience multiple co-morbidities and are prescribed multiple medications thereby increasing the risk of adverse drug events, drug — drug and drug — disease interactions..$^{[5,6]}$

Age-related physiological changes alter the pharmacokinetics and pharmacodynamics. ${ }^{[7]}$ Some drugs pose special risks to older people as a result of these changes, e.g., prolonged sedation and increased risk of falls with long-acting benzodiazepine ${ }^{[8]}$ or increased risk of upper gastrointestinal bleeding with nonsteroidal anti-inflammatory drugs (NSAIDs) ${ }^{[9]}$ Prescription of such drugs are potentially inappropriate, particularly where safer alternatives exist. Hence, screening of potentially inappropriate medications (PIMs) appears compelling. Several explicit and implicit criteria-based prescribing tools, e.g., beers criteria, inappropriate prescribing in the elderly tool, Screening Tool of Older Persons' potentially inappropriate prescriptions, screening tool to alert doctors to the 
right treatment, medication appropriateness index, etc.; have been devised using expert reviews and opinions to identify PIMs. ${ }^{[10]}$ Among these, Beers criteria are the most widely referred tool internationally because of their high reliability and reproducibility. They were first described in 1991 and afterwards extended and updated in 1997 and 2003. ${ }^{[11]}$ In 2012, the 2003 Beers criteria were updated with the partnership of The American Geriatrics Society (AGS) for regular, transparent, systematic updates and support for the extensive use of the criteria by clinicians for their use in research, policy, and practice. ${ }^{[12]}$

Published literature related to the epidemiology of PIM use in elderly in this part (Odisha state) of the country is limited. With this background, the study was initiated to find out the prevalence of PIMs in elderly in a tertiary care hospital in Odisha using the 2012 AGS beers criteria.

\section{MATERIALS AND METHODS}

\section{Study design and setting}

This was a hospital-based cross-sectional study, conducted in M.K.C.G. Medical College and Hospital, a 1000 bedded tertiary care teaching hospital with 19 out-patients departments (OPD) in Eastern India from October 2013 to August 2014.

\section{Sample size and sampling frame}

The source population was elderly patients aged 65 years and more. Assuming a prevalence of $25 \%$, confidence interval (CI) of $95 \%$, the total sample size was determined to be 801 , the response rate was $87.39 \%$, and therefore the final sample size was 700.700 new as well as old patients of either sex who had completed 65 years of age as on $30^{\text {th }}$ September 2013 attending the OPD of General medicine, Surgery, Gynecology, Orthopedics, Psychiatry, Skin, tuberculosis and chest, Ophthalmology, ENT, Oncology and Dentistry were included as majority of geriatric disease fall within the preview of the departments. A time period of 1-month each in a sequential manner was spent in each of the departments' OPD. Patients were randomly included (convenience sample collected opportunistically). All the patients participating in the study were explained clearly about the purpose and nature of the study in the local language (odia) or in any other language they could understand. Written informed consent was obtained before including them in the study. Patients unable to communicate, seriously ill requiring Intensive Care Unit admission or unwilling to participate and those having incomplete information were excluded from the study.

\section{Data collection procedures}

The data were collected by trained data collectors who were supervised daily. All the included patients were interviewed only once, and their prescriptions were checked individually for the necessary information to fill-up the case record forms. Treatment given on that day was considered as one prescription. Then the prescriptions were audited by the authors.

\section{Data processing and analysis}

The data collected through the structured case record form were entered and analyzed using SPSS-20.0 (IBM Corp., NY). Besides, the data were checked and cleaned for their completeness and errors in data entering. To explain the study population in relation to the relevant variables, descriptive statistics were used. Multivariate logistic regression analysis was used to evaluate the influence of age, gender, co-morbidity and number of medications on PIM.

\section{Study instrument}

2012 AGS beers criteria were used to analyze the inappropriateness of the prescriptions. It is a comprehensive set of explicit criteria that gives status to a drug as appropriate or inappropriate for the elderly aged 65 years and above in given conditions. ${ }^{[13]}$ Fifty-three inappropriate medications or medication classes included in the 2012 AGS beers criteria, which are categorized into three categories are as the PIMs and classes to avoid in elderly patients (Category A), medications and classes to avoid in elderly patients with certain diseases and syndromes (Category B) or medications to be used with caution in elderly (Category C). A prescription was considered to be inappropriate if it contained one or more drugs included in 2012 AGS beers criteria.

\section{Ethical consideration}

Ethical clearance was obtained from the Institutional Ethics Committee of MKCG Medical College, Berhampur, Odisha. The data collectors obtained the information after obtaining the consent from each participant.

\section{RESULTS}

Of the 700 patients, $423(60.42 \%)$ were males and 277 $(39.57 \%)$ were females. The average age of the patients was $65.48 \pm 4.37$ years, the overall age range being $65-89$ years. The average diagnosis per patient was found to be $3.18 \pm 1.34$. Most of the patients presented with an acute medical problem on a background of chronic illness. 98 (14\%) patient were diagnosed to have one disease, followed by $226(32.28 \%)$ patients were having two diseases and $376(54.72 \%)$ patients were found to have three or more diseases. On the system wise analysis of the diagnoses, it was found that cardiovascular disorders $(27.65 \%)$ were most common, followed by endocrine system disorders $(20.16 \%)$, infectious diseases such as malaria, pneumonia, etc., (16.57\%), and digestive system disorders $(11.78 \%)$.

The average number of medicines per prescription was $8.17 \pm$ 3.69. The total numbers of drugs prescribed were 5976 in 700 prescriptions. Among them, only 16\% drugs were prescribed in their generic names and the rest were prescribed in their brand names. On the category-wise distribution of the prescribed drugs, it was found that antimicrobials drugs (21.64\%) were 
most frequently prescribed drugs, followed by drugs acting on cardiovascular system (19.75\%), endocrine system $(16.83 \%)$, analgesic and anti-inflammatory drugs (14.34\%), vitamin, minerals and dietary supplements $(12.35 \%)$ and gastrointestinal system (9.16\%). Among the antibiotics, $3^{\text {rd }}$-generation cephalosporin was the most widely prescribed antibiotic, followed by quinolones. Among drugs prescribed for central nervous system disorders $(5.93 \%)$, benzodiazepines such as alprazolam and lorazepam were the commonest.

Potentially inappropriate medications were received by 153 (21.86\%) patients. 112 prescriptions had one PIM; 35 had two and 6 had three PIMs concurrently. None received $>3$ PIMs. Inappropriate medications were most frequent when the diagnoses were cerebral malaria, hypertension, congestive cardiac failure, type-2 diabetes mellitus, urinary tract infection and cerebrovascular accident.

A total of 5976 drugs were prescribed, of which 5691 (96.65\%) were prescribed appropriately and 200 (3.35\%) were prescribed inappropriately. According to categories of inappropriate prescribing described in 2012 AGS Beers Criteria, majority of prescription fell in category A, followed by category B and category C, respectively, [Table 1].

Elderly patients in the age group of 65-74 years received maximum number of inappropriate drugs. It was also observed that $15.29 \%$

\begin{tabular}{|c|c|}
\hline Category of inappropriate prescribing & Number of drugs (\%) \\
\hline A & $128(64.08)$ \\
\hline $\mathrm{B}$ & $50(24.76)$ \\
\hline $\mathrm{C}$ & $22(11.17)$ \\
\hline
\end{tabular}

of patients were prescribed with $>11$ drugs. 165 (23.57\%) patients had $>$ three co-existing diseases. These patients received a higher number of inappropriate medications. Using logistic regression analysis, it was identified that increased number $(\geq 11)$ of concurrent medications use (odds ratio: 1.95, CI: 1.19-3.01, $P \leq 0.01$ ) was the predictor of inappropriate medication but age, gender and comorbidity were not predictors of inappropriate drug use [Table 2].

Some of the PIMs identified in this study were, psychoactive medications such as benzodiazepines, tricyclic-antidepressants, first-generation antihistamines and medications that increase the probability of falls in elderly like vasodilators, antimicrobials and inappropriate use of NSAIDs [Table 3].

\section{DISCUSSION}

The prevalence of PIMs by 2012 AGS beers criteria in our study was $21.86 \%$. Similar studies done in Ahmadabad, ${ }^{[14]}$ and Bangalore ${ }^{[15]}$ have reported a prevalence of $23.59 \%$ and $23.5 \%$, respectively. Some other studies done in France, ${ }^{[16]}$ US, ${ }^{[17]}$ Nepal, ${ }^{[18]}$ Brazil, and Nigeria ${ }^{[5,19]}$ have reported an inappropriate medication to an extent of $66 \%, 32 \%, 53 \%, 37.6 \%, 45.6 \%$, respectively. Few studies carried out in Switzerland, ${ }^{[20]}$ Australia, ${ }^{[21]}$ and Japan ${ }^{[22]}$ have reported a lower PIM than ours. The difference in prevalence of PIMs reported in various studies may be due to the differences in patient and disease characteristics, prescribing patterns and availability of medications listed in 2012 AGS beers criteria. It may also be due to less number of drugs being enlisted in 2012 AGS beers criteria. A geographical variation among physicians' awareness of regarding the existence of a list of inappropriate drugs for the elderly may have led to differences in prevalence of PIM.

In this study, percentage of drugs prescribed by generic names so also the number of drugs written in a single encounter $(8.17 \pm 3.69)$ found to be higher than the WHO recommendation. ${ }^{[23]}$ This finding has clinical relevance in elderly patients as increased number of drugs not only increases the adverse drug events but

\begin{tabular}{|c|c|c|c|c|c|}
\hline Patient characteristics & $\begin{array}{c}\text { Number of patients } \\
(n=700)\end{array}$ & $\begin{array}{c}\text { Number of patients with } \\
\text { PIM }(n=153)\end{array}$ & OR & $95 \% \mathrm{Cl}$ & Significance \\
\hline \multicolumn{6}{|l|}{ Gender } \\
\hline Female & 277 & 56 & 1 (reference) & - & - \\
\hline Male & 423 & 97 & 1.5 & $0.87-1.91$ & 0.261 \\
\hline \multicolumn{6}{|l|}{ Age (in years) } \\
\hline $65-74$ & 326 & 98 & 1 (reference) & - & - \\
\hline $75-84$ & 296 & 46 & 1.2 & $0.72-1.85$ & 0.142 \\
\hline$>85$ & 78 & 9 & 1.68 & $0.92-3.04$ & 0.098 \\
\hline \multicolumn{6}{|l|}{ Number of medications } \\
\hline$<5$ & 418 & 28 & 1 (reference) & - & - \\
\hline $5-10$ & 175 & 46 & 1.13 & $0.88-4.32$ & 0.104 \\
\hline$>11$ & 107 & 79 & 1.95 & $1.19-3.01$ & 0.01 \\
\hline \multicolumn{6}{|l|}{ Number of diseases } \\
\hline $1-2$ & 427 & 89 & 1 (reference) & - & - \\
\hline$\geq 3$ & 273 & 64 & 2.37 & $0.96-1.64$ & 0.087 \\
\hline
\end{tabular}

$n=$ Total number of cases, Significance $=P<0.05 . \mathrm{Cl}=$ Confidence interval, OR = Odds ratio 


\begin{tabular}{lc} 
Table 3: PIMs use in elderly according to organ \\
system or therapeutic category or drug $(\boldsymbol{n}=\mathbf{2 0 0})$ \\
\hline PIM & Frequency (\%) \\
\hline Lorazepam & $36(18)$ \\
Chlorpheniramine maleate & $35(17.5)$ \\
Alprazolam & $34(17)$ \\
Dicyclomine & $24(12)$ \\
Amitriptyline & $11(6)$ \\
Nitrofurantoin & $10(5)$ \\
Nifedipine & $6(3)$ \\
Digoxin & $18(9)$ \\
Doxazosin & $15(7.5)$ \\
Diclofenac in APD & $5(2.5)$ \\
Others & $6(3)$ \\
\hline PIMs = Potentially inappropriate medications, APD = Antipsychotic drug
\end{tabular}

$\mathrm{PIMs}=$ Potentially inappropriate medications, $\mathrm{APD}=$ Antipsychotic drug

also the cost of treatment. In a Singapore-based study higher (70.04\%) inappropriate drug was associated with high (58.59\%) prevalence of polypharmacy. ${ }^{[2]}$ Lau et al. have observed that as the number of diagnosis increases, the number of medications to treat each particular disease condition also increases and this lead to inappropriate medications. ${ }^{[25]}$

Many studies have associated age, gender, multiple medications, and co-morbidity with increased risk of PIM. ${ }^{[14,24,26]}$ In our study age, gender, co-morbidity did not predict inappropriate prescribing. This could be due to the fact that, many of the medications used to treat some of the diseases in the study population were not included as inappropriate in beers criteria. Noninclusion of indoor patients was a limitation of this study and may not be totally generalized to all elderly patients.

\section{CONCLUSION}

Inappropriate prescribing to elderly patients is common and is influenced by the total number of drugs prescribed to an elderly patient. The prescription pattern suggests the need to establish rational drug therapy. PIM in elderly leads to adverse drug reactions, increased morbidity and mortality, increased cost and decreased quality of life. Much of the drug-related inappropriateness and morbidity in the elderly population can be prevented by following rational use of the drug. Endeavors to improve the appropriateness in medication selection for older people are warranted. Therefore, sensitization and training of the healthcare providers about the existence of a list of inappropriate medications for the elderly population at all the levels of healthcare will aid this vulnerable population. Though Beers criteria are widely accepted, there should be a debate whether this criteria is suitable for Indian population or not. National Program for Healthcare of Elderly should envisage and intervene in formulating appropriate criteria Indian elderly. Large scale studies are required on the pattern of inappropriate prescribing to reduce potentially adverse health outcomes cost of treatment and increase compliance in elderly patients.

\section{REFERENCES}

1. Caruso LB, Silliman RA. World demography of aging. In: Loscalzo J, Fauci AS, Braunwald E, editors. Harrisons Principles of Internal Medicine. $18^{\text {th }}$ ed. New York: McGraw Hill; 2012. p. 553-62.

2. Wieland GD. Health \& ageing in international context. Indian J Med Res 2012;135:451-3.

3. Monane M, Matthias DM, Nagle BA, Kelly MA. Improving prescribing patterns for the elderly through an online drug utilization review intervention: A system linking the physician, pharmacist, and computer. JAMA 1998;280:1249-52.

4. Eze UI, Olowu AO. Prescribing patterns and inappropriate use of medications in elderly outpatients in a tertiary hospital in Nigeria. Trop J Pharm Res 2011;10:19-25.

5. Hines LE, Murphy JE. Potentially harmful drug-drug interactions in the elderly: A review. Am J Geriatr Pharmacother 2011;9:364-77.

6. Goldberg RM, Mabee J, Chan L, Wong S. Drug-drug and drug-disease interactions in the ED: Analysis of a high-risk population. Am J Emerg Med 1996;14:447-50.

7. Mangoni AA, Jackson SH. Age-related changes in pharmacokinetics and pharmacodynamics: Basic principles and practical applications. $\mathrm{Br} \mathrm{J}$ Clin Pharmacol 2004;57:6-14.

8. Tinetti ME. Clinical practice. Preventing falls in elderly persons. N Engl J Med 2003;348:42-9.

9. Gabriel SE, Jaakkimainen L, Bombardier C. Risk for serious gastrointestinal complications related to use of nonsteroidal anti-inflammatory drugs. A meta-analysis. Ann Intern Med 1991;115:787-96.

10. National Medicines Information Centre. St. James's hospital. Dublin 8. NMIC Bulletin on Prescribing in the Elderly 2010; 16: 3. Available from: http://www.nmic.ie. [Last accessed on 2010 Jul 15].

11. Dimitrow MS, Airaksinen MS, Kivelä SL, Lyles A, Leikola SN. Comparison of prescribing criteria to evaluate the appropriateness of drug treatment in individuals aged 65 and older: A systematic review. J Am Geriatr Soc 2011;59:1521-30.

12. Marcum ZA, Hanlon JT. Commentary on the new American Geriatric Society Beers criteria for potentially inappropriate medication use in older adults. Am J Geriatr Pharmacother 2012;10:151-9.

13. Fick D, Semla T, Beizer J, Brandt N, Dombrowski R, DuBeau CE, et al. American Geriatrics Society updated Beers Criteria for potentially inappropriate medication use in older adults. J Am Geriatr Soc 2012;60:616-31.

14. Zaveri HG, Mansuri SM, Patel VJ. Use of potentially inappropriate medicines in elderly: A prospective study in medicine out-patient department of a tertiary care teaching hospital. Indian J Pharmacol 2010;42:95-8

15. Harugeri A, Joseph J, Parthasarathi G, Ramesh M, Guido S. Potentially inappropriate medication use in elderly patients: A study of prevalence and predictors in two teaching hospitals. J Postgrad Med 2010;56:186-91.

16. Laroche ML, Charmes JP, Nouaille Y, Fourrier A, Merle L. Impact of hospitalisation in an acute medical geriatric unit on potentially inappropriate medication use. Drugs Aging 2006;23:49-59.

17. Cartwright OM, Moulin J, Hale LS. A Retrospective Evaluation of Potentially Inappropriate Medication use in Hospitalized Elderly Patients. Proceedings of the $3^{\text {rd }}$ Annual GRASP Symposium, Wichita State University; 2007. p. 41-2.

18. Sapkota S, Pudasaini N. Drug Prescribing pattern and prescription error in elderly: A retrospective study of inpatient record. Asian J Pharm Clin Res 2011;4:129-32.

19. Faustino CG, Martins Mde A, Jacob-Filho W. Potentially inappropriate medication prescribed to elderly outpatients at a general medicine unit. Einstein 2011;9:18-23.

20. Egger SS, Bachmann A, Hubmann N, Schlienger RG, Krähenbühl S. Prevalence of potentially inappropriate medication use in elderly patients: Comparison between general medical and geriatric wards. Drugs Aging 2006;23:823-37.

21. Woodward M, Katz B, Elliott R, Vernon G, Tanner F, Saunders R. Problems with Medication Use in the Elderly: An Australian Perspective. J Pharm Pract Res 2006;36:58-66. 
22. Niwata S, Yamada Y, Ikegami N. Prevalence of inappropriate medication using Beers criteria in Japanese long-term care facilities. BMC Geriatr 2006;6:1.

23. WHO DAP, INRUD (1993). How to Investigate Drug Use in Health Facilities, p. 14-45.

24. Mamun K, Lien CT, Goh-Tan CY, Ang WS. Polypharmacy and inappropriate medication use in Singapore nursing homes. Ann Acad Med Singapore 2004;33:49-52.

25. Lau DT, Mercaldo ND, Harris AT, Trittschuh E, Shega J, Weintraub S. Polypharmacy and potentially inappropriate medication use among community-dwelling elders with dementia. Alzheimer Dis Assoc Disord
2010;24:56-63.

26. World Health Organization. World Health Day-7 April. Geneva: United Nations. Available from: http://www.who.int/world-health-day/en/. [Last accessed on 2014 Sep 23].

How to cite this article: Pradhan S, Panda A, Mohanty M, Behera JP, Ramani YR, Pradhan PK. A study of the prevalence of potentially inappropriate medication in elderly in a tertiary care teaching hospital in the state of Odisha. Int J Med Public Health 2015;5:344-8.

Source of Support: Nil, Conflicts of Interest: None declared. 